\title{
Large bowel obstruction due to impaction of a gallstone
}

\author{
Tejinderjit Singh Athwal, ${ }^{1,2}$ Nicholas Howard, ${ }^{2}$ Jane Belfield, ${ }^{3}$ Ufuk Gur ${ }^{2}$
}

1Department of Surgery and Oncology, Royal Liverpool University Hospital, Liverpool, UK;
2Department of Colorectal Surgery, Royal Liverpool University Hospital, Liverpool, UK;
3Department of Radiology, Royal Liverpool University Hospital, Liverpool, UK

Correspondence to Mr Tejinderjit Singh Athwal, tsathwal@doctors.org.uk

\section{Summary}

Gallstone ileus is a complication of cholelithiasis resulting from a fistula between the gallbladder and the gastrointestinal tract. If sufficiently large, a gallstone may lodge at the narrowest part of the gastrointestinal tract, usually the terminal ileum, and present with small bowel obstruction. Here the authors present the unusual case of an 82-year-old man who developed symptoms and signs of large bowel obstruction due to an untreated gallstone, measuring $7 \times 4.5 \mathrm{~cm}$, that fistulated into the transvere colon and subsequently impacted in the sigmoid colon. An emergency laparotomy with sigmoid colotomy was undertaken to remove the obstructing gallstone, and the patient made a full recovery.

\section{BACKGROUND}

Gallstone ileus is infrequent though important cause of mechanical bowel obstruction. The condition is seen more commonly in the older who often have significant other co-morbidities, and the diagnosis is usually delayed due to the insidious nature of the disease. As a consequence there is a high morbidity and mortality associated with gallstone ileus. We report an unusual case of a patient presenting with large bowel obstruction, due to gallstone ileus of the colon, and how expedient investigations and management led to a successful outcome.

\section{CASE PRESENTATION}

An 82-year-old male presented with a 2 week history of constipation, followed by 3 days of absolute constipation and 1 day of intractable postprandial vomiting. He described colicky central and lower abdominal pain and felt bloated. Physical examination revealed a dehydrated patient with a tachycardia of $110 \mathrm{bpm}$ and a tachypnoea of 20. The abdomen was tender but with no signs of peritonitis, grossly distended with hyperactive and high-pitched bowel sounds. Six months previously, the patient had presented with right upper quadrant pain and jaundice and been treated for choledocholithiasis by endoscopic retrograde cholangiopancreatography (ERCP) and sphincterotomy. CT at the time had shown the presence of a large gallstone occupying the entire gallbladder, which did not show signs of inflammation. However, due to the patient's cardiorespiratory co-morbidities, there had been no plans for an elective cholecystectomy.

\section{INVESTIGATIONS}

Laboratory tests on admission showed a leucocytosis of $11400 / \mu 1$ and an elevated C reactive protein of $187 \mathrm{mg} / \mathrm{l}$. Renal and liver function tests were normal and the serum amylase was not raised.

The plain abdominal x-ray showed a dilated transverse colon, pneumobilia and a calcified opacity in the pelvis (figure 1). These unusual findings were further evaluated with a CT scan that confirmed air within the biliary tree and demonstrated a communication between the gallbladder and distended hepatic flexure in keeping with a cholecystocolonic fistula (figure $2 \mathrm{a}$ ). The colon was dilated and fluid filled up to the proximal sigmoid colon where a transition point was seen distal to a large gallstone (figure 2B). Subsequent review of the patient's previous imaging revealed a CT scan, taken 6 months earlier, showing the gallstone within the gallbladder (figure 2C).

\section{TREATMENT}

Once the diagnosis had been established, efforts were made to avoid surgery and extract the gallstone in a less

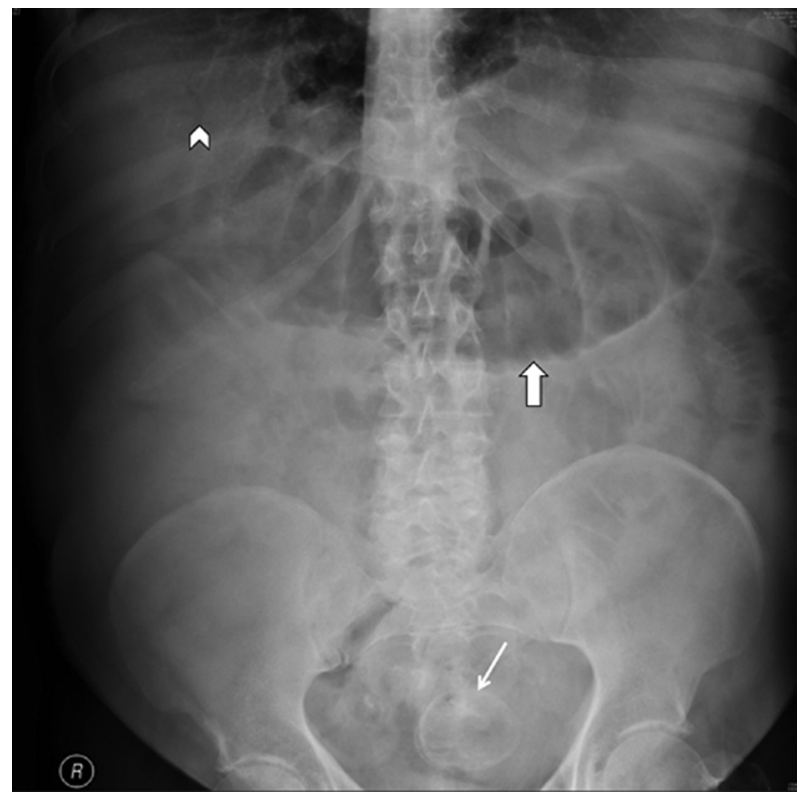

Figure 1 Abdominal radiograph showing dilated large bowel (thick arrow) with a rounded opacity lying in the pelvis (thin arrow) and subtle sign of pneumobilia (arrowhead). 
invasive manner. Consideration was given to extracorporeal lithotripsy, but discussion with a consultant urologist led us to believe that this would be unlikely to succeed given the large size of the stone. Therefore, after fluid and electrolyte supplementation, an emergency laparotomy was performed. The gallstone was found firmly lodged in the sigmoid colon, which itself was thickened, oedematous and inflamed by local trauma caused by the gallstone. Attempts to deliver the gallstone into the rectum to allow retrieval via the anus where unsuccessful, as were attempts to milk it proximally into a normal segment of colon. The sigmoid colon was therefore mobilised and a colotomy performed to deliver the $7 \times 4.5 \times 4 \mathrm{~cm}$ gallstone (figure $2 \mathrm{D}$ ). There was surprisingly no evidence of either a benign or malignant stricture of the sigmoid colon and the obstruction appeared to be solely due to the large size of the gallstone. It was felt that primary closure of the colotomy had a significant risk of failure, therefore, a loop sigmoid colostomy was fashioned. No attempts were made to treat the cholecystocolonic fistula.

\section{OUTCOME AND FOLLOW-UP}

The patient made an uneventful recovery and was discharged home. He was seen in the out patients clinic and was managing his stoma well.
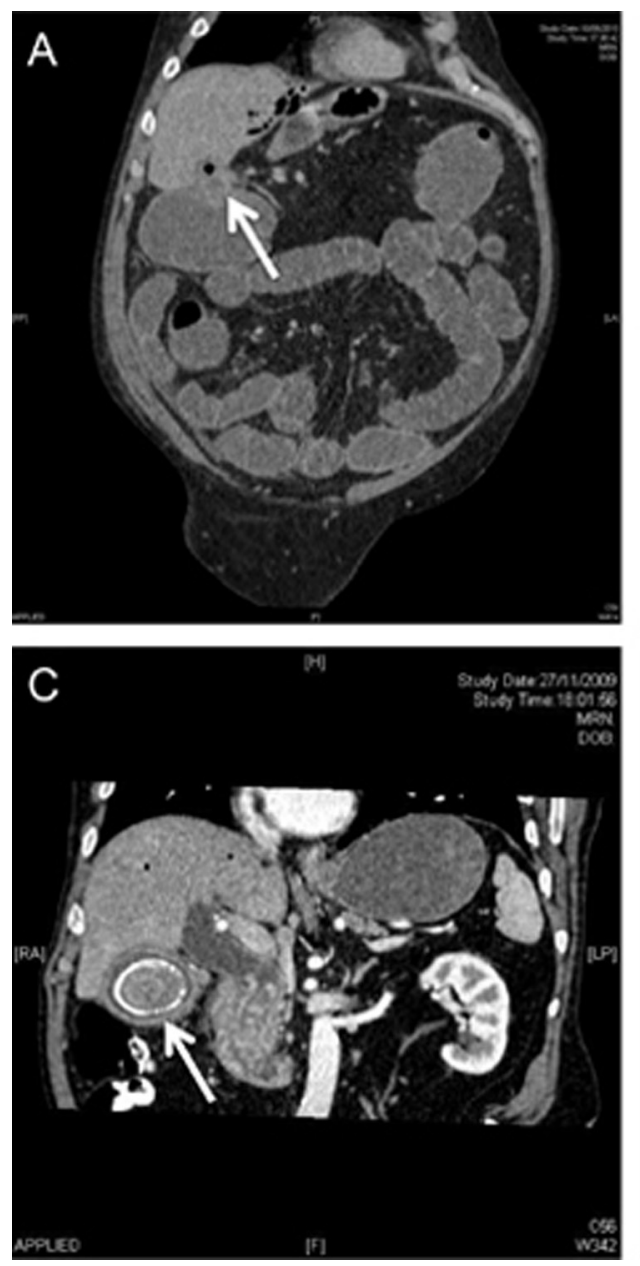

\section{DISCUSSION}

Gallstone ileus is a rare complication of cholelithiasis accounting for $1-4 \%$ of mechanical intestinal obstruction but can account for up to $25 \%$ of small bowel obstruction in patients older that 65 years. ${ }^{12}$ The gallstone usually passes via a biliary-enteric fistula and may impact anywhere in the gastrointestinal tract providing it is over 2.5 $\mathrm{cm}$ in size. ${ }^{3}$ In a review of 1001 cases of gallstone ileus, ${ }^{2}$ the most common sites of impaction were the terminal ileum and ileocaecal valve, and rarely in the jejenum, duodenum or stomach, with impaction in the colon, as seen in our case, occurring in $4 \%$ of patients. ${ }^{2}$

Symptoms of gallstone ileus can be insidious and vague. The classical Rigler's triad of pneumobilia, dilated small bowel with paucity of air in the large bowel and an opacity in the right iliac fossa, is seen on plain abdominal x-ray in less than $50 \%$ of cases. ${ }^{4}$ When a gallstone causes obstruction at an unusual site plain abdominal x-ray may still exhibit modified features of Rigler's triad, however, these may not be immediately obvious and therefore a high index of clinical suspicion is required and a CT scan is considered the gold standard in diagnosis with a sensitivity of $93 \%$ and specificity of $100 \% .^{5}$

As gallstone ileus is a condition seen in an older population, usually with other co-morbid conditions, surgical
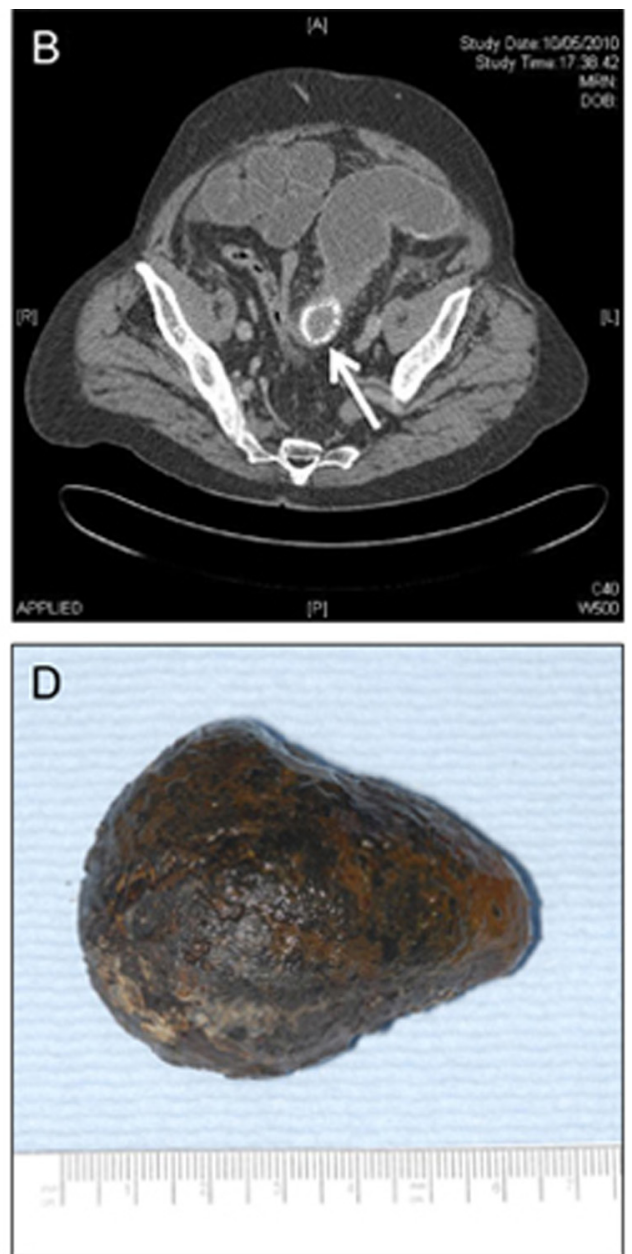

Figure 2 CT shows a chole-colic fistula, with air seen in the biliary tree (A), dilated fluid filled proximal sigmoid, collapsed distal sigmoid and a gallstone at the transition point (B), an earlier CT showing the gallstone in the gallbladder (C) and a picture of the gallstone after surgical removal (D). 
management is associated with a high risk of morbidity and mortality. ${ }^{6}$ In an effort to circumvent surgery, less invasive techniques involving colonoscopy to access the gallstone and relieve the obstruction by fragmentation using lithotripsy, have been successfully employed. ${ }^{7}$ However, these measures are limited by local expertise as well as the size and composition of the impacted gallstone. To reduce the surgical insult of an open laparotomy, and thus reduce the morbidity, there have been reports of laparoscopic enterolithotomy to treat gallstone ileus. ${ }^{7} 9$ These techniques, though feasible, require laparoscopic proficiency and must avoid a prolonged operation.

There is surgical debate as to whether patients with gallstone ileus should have a combination procedure of enterolithotomy to retrieve the gallstone, and simultaneous cholecystectomy and closure of the fistula ${ }^{10} 11$ or enterolithotomy alone to resolve the immediate bowel obstruction. ${ }^{12}$ By undertaking a simultaneous cholecystectomy and closure of the fistula, the risk of further stone formation and cholangitis are reduced, but a prolonged procedure significantly increases the likelihood of postoperative morbidity for the patient. The is also a risk of developing secretory diarrhoea due to the passage of bile salts directly into the large bowel if the cholecystocolonic fistula is not repaired. ${ }^{13}$ However, if this symptom does occur then it can be medically managed with the use of the bile acid sequestrant cholestyramine, or with ERCP and sphincterotomy that allows bile to flow unimpeded into the duodenum. ${ }^{13}$ The traditional approach of enterolithotomy alone to resolve the bowel obstruction, with treatment of the fistula as a second procedure if indicated, remains appropriate in older patient with significant medical co-morbidities. A thorough search of the entire large and small bowel should be undertaken at the time of laparotomy to exclude the presence of any further stones. In our case, it was considered unlikely that the patient would experience further episodes of gallstone ileus as there was no evidence of a second large retained gallstone within the gallbladder and, alongside a previous sphincterotomy, a large cholecystocolonic fistula would allow easy drainage of any small stones. There is a small risk of developing cancer in a diseased gallbladder, however, this risk must be clinically stratified against the risks of cholecystectomy in an older patient.

\section{Learning points}

- Gallstone ileus is an uncommon cause of mechanical bowel obstruction that requires a high index of suspicion to avoid a delay in diagnosis.

- CT scan is the gold standard for diagnosis and should be performed expediently.

-When available, previous imaging can be a valuable tool in establishing the diagnosis.

- The mainstay of treatment in these older patients is to relieve the bowel obstruction and avoid a prolonged operation.

Competing interests None

Patient consent Obtained.

\section{REFERENCES}

1. Clavien PA, Richon J, Burgan S, et al. Gallstone ileus. Br J Surg 1990;77:737-42.

2. Reisner RM, Cohen JR. Gallstone ileus: a review of 1001 reported cases. Am Surg 1994;60:441-6.

3. Rodríguez Hermosa JI, Codina Cazador A, Gironès Vilà J, et al. [Gallstone lleus: results of analysis of a series of 40 patients]. Gastroenterol Hepatol 2001;24:489-94

4. Lassandro F, Gagliardi N, Scuderi M, et al. Gallstone ileus analysis of radiological findings in 27 patients. Eur $\mathrm{J}$ Radiol 2004;50:23-9.

5. Yu CY, Lin CC, Shyu RY, et al. Value of CT in the diagnosis and management of gallstone ileus. World J Gastroenterol 2005:11:2142-7.

6. Illuminati G, Bartolucci R, Leo G, et al. Gallstone ileus: report of 23 cases with emphasis on factors affecting survival. Ital J Surg Sci 1987;17:319-25.

7. Zielinski MD, Ferreira LE, Baron TH. Successful endoscopic treatment of colonic gallstone ileus using electrohydraulic lithotripsy. World J Gastroenterol 2010;16:1533-6.

8. Bourke MJ, Schneider DM, Haber GB. Electrohydraulic lithotripsy of a gallstone causing gallstone ileus. Gastrointest Endosc 1997;45:521-3.

9. Moberg AC, Montgomery A. Laparoscopically assisted or open enterolithotomy for gallstone ileus. Br J Surg 2007;94:53-7.

10. Riaz N, Khan MR, Tayeb M. Gallstone ileus: retrospective review of a single centre's experience using two surgical procedures. Singapore Med J 2008;49:624-6

11. Tan YM, Wong WK, Ooi LL. A comparison of two surgical strategies for the emergency treatment of gallstone ileus. Singapore Med J 2004:45:69-72.

12. Ravikumar $\mathbf{R}$, Williams JG. The operative management of gallstone ileus. Ann R Coll Surg Eng/ 2010;92:279-81.

13. Toll EC, Kelly MD. Successful management of cholecystocolic fistula by endoscopic retrograde cholangiopancreatography: a report of two cases. Hong Kong Med J 2010;16:406-8. 


\section{BMJ Case Reports}

This pdf has been created automatically from the final edited text and images.

Copyright 2012 BMJ Publishing Group. All rights reserved. For permission to reuse any of this content visit http://group.bmj.com/group/rights-licensing/permissions.

BMJ Case Report Fellows may re-use this article for personal use and teaching without any further permission.

Please cite this article as follows (you will need to access the article online to obtain the date of publication).

Athwal TS, Howard N, Belfield J, Gur U. Large bowel obstruction due to impaction of a gallstone. BMJ Case Reports 2012;

10.1136/bcr.11.2011.5100, Published XXX

Become a Fellow of BMJ Case Reports today and you can:

- Submit as many cases as you like

- Enjoy fast sympathetic peer review and rapid publication of accepted articles

- Access all the published articles

Re-use any of the published material for personal use and teaching without further permission

For information on Institutional Fellowships contact consortiasales@bmjgroup.com

Visit casereports.bmj.com for more articles like this and to become a Fellow

Keep up to date with all published cases by signing up for an alert (all we need is your email address) http://casereports.bmj.com/cgi/alerts/etoc 